\title{
Research Paper: The Effectiveness of Choice Theory Education on Happiness and Self-esteem in University Students
}

\author{
Hamidreza Fereidouni ${ }^{1}$ (D), Abdollah Omidi², Shima Tamannaeifar ${ }^{3 *}$ (D)
}

1. Department of Psychology, Faculty of Education \& Psychology, Khorasgan Branch, Islamic Azad University, Isfahan, Iran. 2. Department of psychiatry, Roozbeh Psychiatry Hospital, Tehran University of Medical Sciences, Tehran, Iran.

3. Department of Clinical Psychology, School of Medicine, Kashan University of Medical Sciences, Kashan, Iran.

\begin{tabular}{|c|c|}
\hline & Chtetion: Fereidouni, H., Omidi, A., \& Tamannaeifar, Sh. (2019). The Effectiveness of Choice Theory Education on Happiness \\
\hline 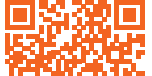 & $\begin{array}{l}\text { and Self-esteem in University Students. Journal of Practice in Clinical Psychology, 7(3), 207-214. http://dx.doi.org/10.32598/ } \\
\text { jpcp.7.3.207 }\end{array}$ \\
\hline atsing & dol'http://dx.doi.org/10.32598/jpcp.7.3.207 \\
\hline
\end{tabular}

\section{(i) (5)}

Article info:

Received: 25 Dec 2018

Accepted: 10 Apr 2019

Available Online: 01 Jul 2019

Keywords:

Choice theory, Happiness, Self-esteem

\section{ABSTRACT}

Objective: The present study examined the effect of choice theory education on the happiness and self-esteem in university students.

Methods: The statistical population consisted of all students of Qom universities. The study sample consisted of 30 students ( 7 males and 8 females per group) with low self-esteem ( 0 out of 10) and happiness (14 out of 87) levels. The subjects were randomly selected and assigned to the experimental and control groups by convenience sampling technique. To conduct the Pre-test and post-test, the Oxford Happiness Questionnaire and Rosenberg Self-esteem Scale were used. The test group members attended the choice theory education program weekly for 5 consecutive weeks, whereas the control group received no treatment.

Results: After implementing the post-test, the collected data were analyzed using the Analysis of Covariance (ANCOVA) in SPSS. The findings indicated that treatment program effectively increased the test group members' happiness $(\mathrm{F}=213.53, \mathrm{P}<0.0005)$ and self-esteem $(\mathrm{F}=0.52$, $\mathrm{P}<0.0005$ ).

Conclusion: The principles of choice theory can be implemented among graduate students to promote their happiness and self-esteem; in turn, it may lead to educational and social achievements.

\section{* Corresponding Author:}

Shima Tamannaeifar, PhD.

Address: Department of Psychiatry, Roozbeh Psychiatry Hospital, Tehran University of Medical Sciences, Tehran, Iran.

Tel: +98 (21) 55419151-9

E-mail:sh-tamannaeifar@farabi.tums.ac.ir 


\section{Highlights}

- Reality therapy is widely used in an educational setting to help students master their own choices.

-As the clients experience small success, their self-esteem improves and directs to more goal-setting and problem-solving.

- Reality therapy focuses on changing thoughts and actions and empowers people to improve their present condition.

\section{Plain Language Summary}

Reality therapy is a revision of choice theory. According to the choice theory, our behavior is the result of the choices we make in our lives, and they are the only things we can control. People are born with 5 basic needs: love, power, freedom, fun, and survival.Therapists help their clients to identify unmet needs and set the goals and guide them by problem solving to reach the goals. The satisfaction of some needs like fun, love, and power and having more appropriate goals lead to increase happiness. Reality therapy, as client-centered psychotherapy, focuses on the present relationship and avoids recalling past events. In reality therapy, people learn to accept responsibility for their behaviors, have more meaningful relationships, and spend less time on what they cannot do directly, such as changing their feelings and physiology. The goal is to help people take internal control to make better choices. This study examines the effectiveness of reality therapy on happiness and selfesteem. The results indicate that students can benefit from the effects of psychotherapy and achieve great results. Since college students have important role in the future of their countries and their choices have vital impact on this period of life, applying reality therapy can be useful to make a better future.

\section{Introduction}

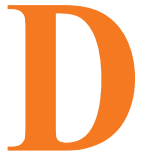

ifferent therapies can enhance individuals' happiness (Barfarazi, Pourghaznein, Mohajer, Mazlom, Asgharinekah 2018; Ansari \& Sabaei, 2019; Heidari, Amiri, \& Amiri, 2016). Reality therapy has been effective in improving happiness. Reality therapy is derived from choice theory (Glasser, 2016), as a revision of control theory (Glasser, 1985). According to the choice theory, we are born with 5 basic needs, including love and belonging, power, freedom, fun, and survival (Wubbolding, 2013). In the choice theory, "quality world" is a set of small pictures, constituted based on the 5 basic needs shortly after the birth and re-create during life (Wubbolding, 2013).

The content of the pictures constitutes of people we want to be with, the things we prefer to own or experience, and the set of beliefs that govern our behaviors (Glasser, 2016). In choice theory training groups, counselors teach people to accept the responsibility of their behaviors, regardless of changing them. The procedure of sessions has to be based on WDEP to select effective choices. WDEP stands for wants, direction and doing, self- evaluation, and planning (Jusoh \& Hussain, 2015). In this regard, some studies reported that having a meaningful life or perusing an appropriate goal are the important predictors of happiness (Klug \&, Maier, 2015; Steca et al., 2016). Another study emphasized on the connectedness and social relations as the sociocultural source of love and belonging need in predicting happiness (Delhey \& Dragolov, 2016).

Self-esteem, as a universal and crucial factor, is related to happiness in people (Brown, 2010). Childhood experiences, the reaction of immediate families, teachers, peers, and authorities develop our basic self-esteem (Yaratan \& Yucesoylu, 2010). The locus of control, derived from Rotter social theory (Serin, Serin, \& Sahin, 2010), is associated with self-esteem. In reality therapy, as one of the most recent psychotherapy approaches, the acceptance of responsibility, satisfaction of basic needs, and internal control lead to identifying success, related to self-esteem (Corey, 2002). The perception of reinforcements and punishments from the environment determine the internal or external type of the locus of control (Serin, Serin, \& Şahin, 2010).

Mateo \& Datu (2012) conceptualized happiness using choice theory. The obtained data suggested that the need for love and belongingness, and the need for fun and enjoy were significantly associated with happiness. Thus, the happiness of Filipino adolescents was linked to their needs for love and belongingness and the need for fun and enjoyment. Howell, Chenot, Hill, \& Howell (2011) found that the psychological need for satisfaction was correlated with momentary happiness and individual dif- 
ferences in life satisfaction which moderated this relationship. In this regard, when autonomy and relatedness needs are met, persons with high levels of life satisfaction experience increased happiness.

Eslami, Hashemian, Jorjani, \& Modarres (2013) argued that reality therapy improved the students' happiness and its related components. Eslami, Hashemian, Jorjani, \& Modarres (2013) also concluded that group reality therapy improves the quality of life, happiness, and the life satisfaction of adolescents with abusive parents in Mashhad.

Furthermore, Moradi Shahrbabak, Ghanbari, \& Aghamohammadian (2011) investigated the effectiveness of reality therapy on improving self-esteem among the students of Ferdowsi University of Mashhad. The relevant results indicated a significant improvement in the self-esteem scores of the experimental group. It can be concluded that reality therapy emphasizes the freedom and responsibility of people and considers behavior as a choice made by the individuals, which affects their mental health. In this approach, health is determined by the sense of responsibility, living at the present moment, making informed choices, awareness about basic needs, and the ability to control problems (Wubbolding, Brickell, Imhof, Lojk, \& AlRashidi, 2004).

The implementation of reality therapy in educational setting is recommended because of its effectiveness. In reality therapy, many maladaptive behaviors are considered as a method of satisfying unmet needs and save time spent on the diagnosis. The counselors help students evaluate their practices based on their need for satisfaction and find appropriate options to meet inner motivations (Wubbolding, 2018). Studies disregarded investigating the happiness and self-esteem of students by choice theory. As a result, the present study investigated the effect of choice theory principles on happiness and self-esteem. Glaser believes that choosing responsible behaviors can lead to a happier life (Glasser, 2016).

Happiness and self-esteem are correlated (Lyubomirsky, Tkach, DiMatteo, 2006); thus, we also considered these variables. University students who form a large number of populations have been endangered by a wide range of stressors that may cause educational failure, health problems, or maladaptive coping mechanisms. Students are among the most important and influential groups of the society and impact the future and progression of the country. Given the movement towards evidence-based practice in the field of counseling, happiness, and academic achievement are significantly as- sociated with each other (Tabbodi, Rahgozar, Mozaffari, 2015). We aimed to assist students in improving their well-being and quality of life. Thus, the present study investigated the effectiveness of teaching choice theory principles on happiness and self-esteem in students.

\section{Methods}

Oxford Happiness Questionnaire (Argyle, Martin, \& Crossland, 1989): This 29-item multiple-choice tool is partly adapted from the Beck Depression Inventory (BDI 1976). Each item of it is answered on a 4-point Likert-type scale, with the total scores ranging from 0 to 87 . Higher scores indicate greater happiness. The respondents are requested to choose the item which best describes their feeling over the past week. According to Argyle et al., (1989), its internal reliability (using Cronbach alpha coefficient) and reliability (by test-retest during 7 weeks) were reported as 0.9 and 0.7 , respectively. Alipour \& Nour-bala (1999) calculated its internal reliability using Cronbach alpha coefficient as 0.98 in 101 students of Tehran Universities, and its test-retest reliability was 0.79 in a 3-week interval. In this study, Cronbach's alpha coefficient for this questionnaire was obtained as 0.75 .

Rosenberg Self-Esteem Scale (RSC) (Rosenberg, 1965): This tool measures the overall self-esteem. The scale consists of 10 questions, 5 of which are negative, and 5 are positive. Each material has two answering options to agree and disagree. The minimum obtainable score for this scale is zero, and the maximum one is 10. The closer a person's score is to 10 , the higher their self-esteem. The RSC internal consistency ranges from 0.77 to 0.88 . Its test-retest reliability ranges from 0.82 to 0.85 . The criterion validity of this test is 0.55 , and its construct validity in correlation with anxiety and depression is -0.64 and -0.54 (Rosenberg, 1965). Ansarin, Jalali, Setarehshenas, Mazloomi, Soltani-Arabshah (2006) calculated the internal consistency reliability of this questionnaire by Cronbach's alpha coefficient equal to 0.84. Arshi, Sadeghi-Bazargani, Mohammadi, Soltan Mohammad Zadeh, Rouhi, Barak (2007) calculated the coefficient of retest for the whole scale with one, two and three weeks intervals as $0.77,0.73$, and 0.78 , respectively. In this study, Cronbach's alpha coefficient for this questionnaire was obtained as 0.79 .

This was a quasi-experimental study with a Pre-testpost-test and control group design. The study population consisted of Qom Universities. Prior to conducting the program, all study participants signed informed consent and completed demographic data questionnaire, RSC, 
Table 1. Choice theory program-William Glasser Institute-Iran

\begin{tabular}{|c|c|}
\hline Sessions & Contents \\
\hline 1 & $\begin{array}{l}\text { Identify the group members names, introduce the goals of the group sessions and the basic principles of choice } \\
\text { theory, explore the basic needs (i.e. love and belonging, fun, freedom, power, and survival) and global behaviors } \\
\text { (i.e. encompasses four4 elements of doing, thinking, feeling, and physiology). }\end{array}$ \\
\hline 2 & Identify members' 5 basic needs (through basic needs test) and how they operate in the real world. \\
\hline 3 & Explore the quality world, encourage members to see what quality is desired by other individual worlds. \\
\hline 4 & Identify conflicts between basic needs and the real world \\
\hline 5 & $\begin{array}{c}\text { Introduce and identifing the } 4 \text { components of behavior, including doing, thinking, feeling, and physiology. } \\
\text { Help participants choose responsible actions and thoughts, leading them to feel better and positively impact their } \\
\text { physiology. }\end{array}$ \\
\hline 6 & Introduce behavior machine and describe related components using behavior machine cards. \\
\hline 7 & $\begin{array}{l}\text { Introduce responsible thought and actions using WDEP. } \\
\text { W: What do I want (goal); D: What am I doing to get what I want?; E: Evaluate: How is that working out for me?; P: } \\
\text { What is my plan of action for accomplishing my goals? }\end{array}$ \\
\hline 8 & Design a suiTable plan to be simple, accessible, affordable, and measurable. \\
\hline
\end{tabular}

and the oxford happiness inventory. Thirty students (7 males and 8 females per group) with low self-esteem (from -10 to +10 ) and happiness (40-42 out of 87) were randomly selected and assigned into the experimental and control groups.

The experimental group received 10 two-hour sessions every other day. The control group received no treatment. After completing the program, both groups completed the post-test questionnaires. The inclusion criteria were being 18-25 years old, being university students, the lack of suffering from psychotic disorders, no psychiatric medication use, the lack of receiving psychotherapy for at least 6 months, no substance abuse and no reported suicidal ideation. The exclusion criteria were absence from more than 3 sessions and any conditions preventing the subject from participating in the study. Table1 presents a description of 8 sessions. The obtained data were analyzed by the Analysis of Covariance (ANCOVA).

\section{Results}

The Mean \pm SD scores were calculated for descriptive purposes. The descriptive statistics of happiness and self-esteem are represented in Tables 2 and 3, respectively. The main analysis was computed using ANCOVA; because statistical studies revealed that controlling the baseline score is superior to pre-post comparisons and increases the test power. As per Table 3, F was not significant for the happiness and self-esteem; thus, the assumption of the equality of variance was confirmed. Considering the other assumption for data analysis, ANCOVA was used.

Table 2. the Pre-test-post-test scores of happiness and self-esteem in the experimental and control groups

\begin{tabular}{cccc}
\hline \multirow{2}{*}{ Variable } & Group & \multicolumn{2}{c}{ Mean \pm SD } \\
\cline { 3 - 4 } & & Pre-test & Post-test \\
\hline Happiness & Experimental & $44.06 \pm 17.05$ & $75.80 \pm 4.78$ \\
& Control & $57.53 \pm 17.77$ & $57.40 \pm 17.77$ \\
Self-esteem & Experimental & $2.53 \pm 1.76$ & $2.53 \pm 1.76$ \\
& Control & $4.93 \pm 2.71$ & $4.93 \pm 2.71$ \\
\hline
\end{tabular}


Table 3. Levene's test results for the equality of variance assumption

\begin{tabular}{|c|c|c|c|c|}
\hline Variable & $\mathbf{F}$ & df 1 & df 2 & $\mathbf{P}$ \\
\hline Happiness & 0.260 & 1 & 28 & 0.614 \\
\hline Self-esteem & 0.515 & 1 & 28 & 0.332 \\
\hline
\end{tabular}

Table 4. ANCOVA results for group choice theory sessions on the happiness and self-esteem

\begin{tabular}{|c|c|c|c|c|c|}
\hline Variables & Effect Source & SS & MS & $\mathbf{F}$ & $\mathbf{P}$ \\
\hline \multirow{2}{*}{ Happiness } & Pre-test & 3069.339 & 3069.339 & 613.242 & 0.001 \\
\hline & group & 6379.97 & 6379.97 & 504.06 & 0.002 \\
\hline \multirow{2}{*}{ Self-esteem } & Pre-test & 106.157 & 106.157 & 91.779 & 0.001 \\
\hline & Group & 0.604 & 0.604 & 0.522 & 0.001 \\
\hline
\end{tabular}

Table 4 reveals that choice theory principles education significantly affected the happiness and self-esteem after adjusting the Pre-test score. The obtained results indicated that choice theory improved the scales mentioned above in the experimental group.

\section{Discussion}

The major assumption of choice theory regarding the satisfaction of basic needs suggests that students who feel free to make choices to express themselves, feel safe, and worthy, and make a satisfactory connection with others are happier than others (Turkdogan, \& Turgut, 2011).

The study results are in line with Eslami, Hashemian, Jorjani, \& Modarres (2013) and Eslami et al., (2013) findings reporting the effectiveness of choice theory on happiness. Although, studies on people encountering with many catastrophizing events such as wars, terrorism, and severe diseases indicated that psychological needs have a more vital role in creating happiness (Chen, Van Assche, Vansteenkiste, Soenens, \& Beyers, 2015). Paul, Jose, Bee, Lim, Fred, \& Bryant. (2012) argued that happiness could be defined as the satisfaction of basic needs and in a collectivistic society in a social context. Collective society rewards behaviors that optimize connectivity through interpersonal skills (Reyes, 2005).

In self- determination theory, the satisfaction of psychological needs mainly connectivity, autonomy, and competence are essential in achieving positive psychological outcomes (David, 2014). Moreover, internally motivated individuals are more capable to experience life satisfaction (Howell et al., 2011). Autonomous people select their behaviors freely and consistent with their values and interest (Kasser \& Ryan, 1996). Turkdogan (2017) believed that survival needs could be considered as a control variable to explore how psychological needs predict happiness.

Reality therapy aims to assist individuals achieve selfresponsibility and empowerment by emotional and cognitive independence, and maintain activity, meet the 5 basic needs (Sauerheber, Graham, Britzman, \& Jenkins, 2016). In this regard, another finding was the effectiveness of choice theory program on self-esteem among the studied students. Glasser, the developer of reality therapy and Purkey, the co-founder of the International Association of Invitational Education encourage the development of most characteristics in people. They view self-esteem as a basis for action, behavior, and decisionmaking. They believe that students' success depends on positive self-esteem enabling students to choose behaviors that provide reward, success, and acceptance of others (Zeeman, 2006). Faulkner \& Burdenski (2011) pointed the relationship between the need for satisfaction and positive coping skills, internal locus of control, academic achievement, and success. According to Timothy, Judge \& Joyce, Bono (2001) the relationship between self-esteem and internal control indicates that people whose source of control is internal have higher self-esteem.

We found that choice theory positively affects individuals' happiness and self-esteem. Happiness and selfesteem influence the quality of life and behaviors in dif- 
ferent ways; thus, it is crucial to investigate those and in turn, improve individuals' mental health. However, choice theory has been applied in psychology subjects beyond the therapeutic approach in adolescence related to social expectations derived from developmental commissions. The small sample size and the lack of follow-up assessment were among the study limitation that should be considered in future studies. In summary, due to the effectiveness of choice theory program on the happiness and self-esteem of students, assigning this program in the education system may enhance mental health capacities and prevent mental disorders.

\section{Ethical Considerations}

\section{Compliance with ethical guidelines}

This research received the ethical approval from Qom Azad University Ethics Committee. The study participants were given written and verbal information about the study. The respondents were anonymous, and all the responses were treated confidentially.

\section{Funding}

This paper was extracted from the master thesis prepared by Hamidreza Fereydouni from Department of Psychology, Faculty of Education \& Psychology, Khorasgan Branch, Islamic Azad University, Isfahan.

\section{Authors' contributions}

Conceptualization: All authors; Methodology, Validation, Formal analysis, Investigation, Resources, Data curation, Writing-original draft preparation: Hamidreza Fereidouni; Writing-review \& editing: Shima Tamannaeifar; Visualization, Project administration: Hamidreza Fereidouni; Supervision: Abdollah Omidi.

\section{Conflict of interest}

The authors declared no conflict of interest.

\section{References}

Alipour, A., \& Noorbala, A. (1999). [Introductory survey on validity and reliability of oxford happiness inventory in Tehran universities (Persian)]. Journal of Thought and Behavior, 5(1), 55-63.
Ansarin, H., Jalali, M. H., Setarehshenas, R., Mazloomi, S., Soltani-Arabshahi, R. (2006). Scabies presenting with bullous pemphigoid-like lesions. Dermatology online journal, 12(1), 19.

Ansari, Y., \& Sanaei, F. (2018). The effect of positive couple therapy on the happiness of mothers of exceptional children. International Archives of Health Sciences, 5, 43-7.

Argyle, M., Martin, M., \& Crossland, J. (1989). Happiness as a function of personality and social encounters. In J. P. Forgas, \& J. M. Innes (Eds.), Recent Advances in Social Psychology: An International Perspective (pp. 189-247). Amsterdam: Elsevier.

Arshi, S., Sadeghi-Bazargani, H., Mohammadi, R., Soltan Mohammad Zadeh, M., Rouhi, A., Barak, M. (2007). Burns comprising $3 / 4^{\text {th }}$ of home injuries in preschool children of rural areas of Ardabil province, Iran. Journal Of Medical Sciences, $7(2), 248-51$.

Barfarazi, H., Pourghaznein, T., Mohajer, S., Mazlom, S., Asgharinekah, S. (2018). Evaluating the Effect of Painting Therapy on Happiness in the Elderly. Evidence Based Care, 8(3), 17-26. [Doi: 10.22038/ebcj.2018.31572.1785]

Brown, R. A. (2010). Perceptions of psychological adjustment, achievement outcomes, and self-esteem in Japan and America. Journal of Cross-Cultural Psychology, 41(1), 51-61. [DOI:10.1177/0022022109349507]

Chen, B., Van Assche, J., Vansteenkiste, M., Soenens, B., \& Beyers, W. (2015). Does psychological need satisfaction matter when environmental or financial safety are at risk? Journal of Happiness Studies, 16(3), 745-66. [DOI:10.1007/s10902-0149532-5]

Corey, G. (2002). Theory and practice of group counseling. California: Brooks/Cole Publishing Company.

David, L. (2014). Self-determination theory (Deci and Ryan). Retrieved from https://www.learning-theories.com/self-determination-theory-deci-and-ryan.html

Delhey, J., \& Dragolov, G. (2016). Happier together. Social cohesion and subjective well-being in Europe. International Journal of Psychology, 51(3), 163-76. [DOI:10.1002/ijop.12149] [PMID]

Eslami, R., Hashemian, P., Jorjani, L., \& Modarres, M. (2015). The effectiveness of group reality therapy approach on happiness and life quality of teenagers with abnormal parents in Mashhad. Journal of Educational and Management Studies, 5(1), 34-40.

Faulkner, B., \& Burdenski, T. K., Jr. (2011). Empowering lowerincome developmental math students to satisfy glasser's five basic needs. International Journal of Choice Theory and Reality Therapy, 31(1), 128-48.

Glasser, W. (2016). Choice theory and the new psychology of personal freedom. Traslated: Ali, Sahebi. Tehran: sayehsokhan publidher.

Glasser, W. (1985). Control theory. New York: Harper Collins

Howell, R. T., Chenot, D., Hill, G., \& Howell, C. J. (2011). Momentary happiness: The role of psychological need satisfaction. Journal of Happiness Studies, 12(1), 1-15. [DOI:10.1007/ s10902-009-9166-1

Heidari, F., Amiri, A., \& Amiri, Z. (2016) The effect of personcentered narrative therapy on happiness and death anxiety 
of elderly people. Abnormal and Behavioural Psychology, 2, 123 . [Doi: 10.4172/2472-0496.1000123]

Jusoh, A. J., \& Hussain, S. P. (2015). Choice Theory and Reality Therapy (CTRT) group counseling module. Asian Journal of Humanities and Social Studies, 3(4), 313-8.

Kasser, T., \& Ryan, R. M. (1996). Further examining the American dream: Differential correlates of intrinsic and extrinsic goals. Personality and Social Psychology Bulletin, 22(3), 280-7. [DOI:10.1177/0146167296223006]

Klug, H. J. P., \& Maier, G. W. (2015). Linking goal progress and subjective well-being: A meta-analysis. Journal of Happiness Studies, 16(1), 37-65. [DOI:10.1007/s10902-013-9493-0]

Lyubomirsky, S., Tkach, C., \& DiMatteo, M. R. (2006). What are the differences between happiness and self-esteem. Social Indicators Research, 78(3):363-404.

Mateo, N. J. C., \& Datu, J. A. D. (2012). Conceptualizing happiness using choice theory. International Journal of Research Studies in Psychology, 1(3), 31-6. [DOI:10.5861/ijrsp.2012.263]

Mohammadi, N. (2005). The preliminary study of validity and reliability of Rosenberg's self-esteem scale. Journal of Iranian Psychologists, 1(4), 55-62.

Moradi Shahrbabak, F., Ghanbari Hashem Abadi, B. A., \& Aghamohammadian Shaarbaf, H. R. (2011). [Effectiveness of group reality therapy on self-esteem among students of Ferdowsi University (Persian)]. Studies in Education and Psychology, 11(2), 227-38.

Paul, E., Jose, A., Bee, T., Lim, A., \& Fred, B. (2012). Does savoring increase happiness? A daily diary study. The Journal of Positive Psychology, 7(3):176-87.

Rajabi, Q. R., \& Bohlol, N. (2007). Reliability and validity of Rosenberg Self-Esteem Scale in first year student of Shahid Chamran University. Journal of Educational and Psychological Research, 3(2), 33-48.

Reyes, J. A. S. (2005). Conceptualizing the happy Filipino: Implicit theories of counselors and students. Philippine Journal of Counseling Psychology, 7(1), 99-113.

Rosenberg, M. (1965). Society and the adolescent self-image. Princeton: Princeton University Press. [DOI:10.1515/9781400876136]

Sauerheber, J. D., Graham, M. A., Britzman, M. J., \& Jenkins, C. (2016). Using reality therapy to facilitate successful aging in clinical practice. The Family Journal, 24(2), 174-81. [DOI:10.1177/1066480716628630]

Serin, N. B., Serin, O., \& Şahin, F. S. (2010). Factors affecting the locus of control of the university students. Procedia-Social and Behavioral Sciences, 2(2), 449-52. [DOI:10.1016/j.sbspro.2010.03.041]

Steca, P., Monzani, D., Greco, A., D’ Addario, M., Cappelletti, E., \& Pancani, L. (2016). The effects of short-term personal goals on subjective well-being. Journal of Happiness Studies, 17(4), 1435-50. [DOI:10.1007/s10902-015-9651-7]

Tabbodi, M., Rahgozar, H., Mozaffari, M., Abadi, M. (2015). The relationship between happiness and academic achievements. European Online Journal of Natural and Social Sciences: Proceedings, 4(1), 241-6.
Timothy, A. J., \& Joyce, E. B. (2001). Relationship of core selfevaluations traits-self-esteem, generalized self-efficacy, locus of control, and emotional stability-with job satisfaction and job performance: A meta-analysis. Journal of Applied Psychology, 86(1), 80-92.

Turkdogan, T. (2017). Exploring the antecedents of happiness: Reconceptualization of human needs with Glasser's choice theory. In A. A Vilas Boas (Eds.), Quality of Life and Quality of Working Life. London: IntechOpen. [DOI:10.5772/68022]

Wubbolding, R. E. (2013). Reality therapy for the $21^{\text {st }}$ century. Abingdon: Routledge. [DOI:10.4324/9780203768457]

Wubbolding, R. E. (2018).Contemporary controversial issue and how to use reality therapy in an ethical and mainstreamed: Thoughts to ponder. International Journal of Choice Theory and Reality Therapy, 1, 58-62.

Wubbolding, R. E., Brickell, J., Imhof, L., Kim, R. I. Z., Lojk, L., \& Al-Rashidi, B. (2004). Reality therapy: A global perspective. International Journal for the Advancement of Counselling, 26(3), 219-28. [DOI:10.1023/B:ADCO.0000035526.02422.0d]

Yaratan, H., \& Yucesoylu, R. (2010). Self-esteem, self-concept, self-talk and significant others' statements in fifth grade students: Differences according to gender and school type. Procedia-Social and Behavioral Sciences, 2(2), 3506-18. [DOI:10.1016/j. sbspro.2010.03.543]

Zeeman, R. D. (2006). Glasser's choice theory and purkey's invitational education-allied approaches to counseling and schooling. Journal of Invitational Theory and Practice, 12, 46-51. 
This Page Intentionally Left Blank 